Check for updates

Cite this: RSC Adv., 2017, 7, 47332

Received 11th April 2017

Accepted 8th May 2017

DOI: $10.1039 / c 7 r a 04129 b$

rsc.li/rsc-advances

\title{
Comment on "Microwave synthesis of graphene/ magnetite composite electrode material for symmetric supercapacitor with superior rate performance" by K. Karthikeyan, D. Kalpana, S. Amaresh and Y. S. Lee, RSC Adv., 2012, 2, 12322 $\uparrow$
}

\author{
Rajaperumal M. iD *
}

Recently, the number of research publications has increased drastically in the field of supercapacitors. Therefore, it is very important to compare and analyse reported results via standardized procedures. Karthikeyan et al. (RSC Adv., 2012, 2, 12322-12328) reported a study titled "Microwave synthesis of a graphene/magnetite composite electrode material for a symmetric supercapacitor". Herein, I demonstrated that Karthikeyan et al. overestimated the electrochemical supercapacitor performance. The actual electrochemical supercapacitor analysis reveals that the supercapacitor performance is much lower than that reported in the abovementioned study. In my opinion, it is very confusing to make a quantitative comparison between their results and the state-of-the-art electrode material performance evolution.
\end{abstract}

\section{Introduction}

The number of studies reported in the supercapacitor field has drastically increased over the past few years. Nowadays, it is commonly observed that the reported data does not match the industrial or technologic requirements due to the use of nonstandardized procedures to compare and analyze the reported results. Herein, I considered RSC Adv., 2012, 2, 12322-12328 as a suitable example to show the existence of this important problem. The charge-discharge profile of the graphene/ magnetite composite electrode material is given in Fig. 4a in the original article ( $R S C A d v$.), where the red curve in the graph corresponds to the $\mathrm{Fe}_{3} \mathrm{O}_{4}$-GNS electrode. The same data is replotted in Fig. 1 for clarity, which is obtained by the author.

\section{For a three-electrode system}

Capacitance has been calculated using the usual capacitance formula given below, where $C$ is the specific capacitance, $I$ is the applied current, $t$ is discharge time, $V$ is the working voltage window, and $m$ is the mass of the electrode active material.

$$
C=\frac{I t}{V m}
$$

Academy of Scientific and Innovative Research (AcSIR), Chennai-600113, TN, India. E-mail: rajaperumalsjc@gmail.com

$\uparrow$ Electronic supplementary information (ESI) available: The data of Fig. 1 is given as origin work sheet in the ESI. See DOI: 10.1039/c7ra04129b
Herein, the discharge time is clearly visible in Fig. 1 (same as Fig. 4a in RSC Adv., 2012, 2, 12322-12328), which is about 61.6 seconds. The voltage window has been fixed at $1 \mathrm{~V}$, which is also visible in Fig. 1. Thus, only $I$ and $m$ are hidden in the data. However, the ratio $I / m$ is given as a constant such as 2,3 , and $5 \mathrm{~A} \mathrm{~g}^{-1}$ by substituting this data in the abovementioned capacitance equation

$$
\begin{gathered}
C=\frac{I t}{V m} \\
C=\frac{2(\mathrm{~A}) \times 61.6(\mathrm{sec})}{1(\mathrm{~V}) \times \mathrm{g}}
\end{gathered}
$$

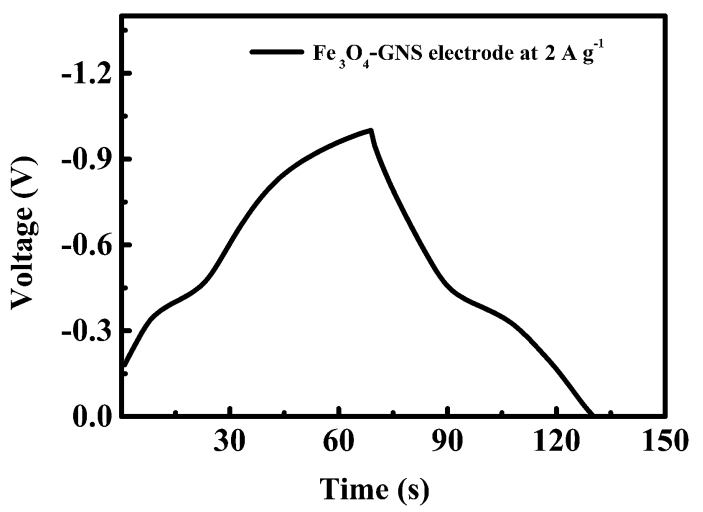

Fig. 1 Charge-discharge profile of the graphene/magnetite composite electrode at a current density of $2 \mathrm{~A} \mathrm{~g}^{-1}$. 


$$
\begin{aligned}
C & =\frac{2 \times 61.6}{1} \\
& =123.2 \mathrm{~F} \mathrm{~g} \mathrm{~g}^{-1}
\end{aligned}
$$

From the abovementioned calculation, the maximum possible capacitance is found to be about $123.2 \mathrm{~F} \mathrm{~g}^{-1}$ for the given data shown in Fig. 4a (RSC Adv., 2012, 2, 12322-12328) (the data from Fig. 1 is given as an origin worksheet in the ESI $\dagger$ ). However, Karthikeyan et al. reported that the capacitance is 415 $\mathrm{F} \mathrm{g}^{-1}$ at $2 \mathrm{~A} \mathrm{~g}^{-1}$, which is nearly four (4) times higher than the actual value (123.2 $\left.\mathrm{F} \mathrm{g}^{-1}\right)$. The same type of disagreement is found in their other reported capacitances for 2,3 , and $5 \mathrm{~A} \mathrm{~g}^{-1}$.

\section{For a two-electrode system}

Capacitance can be calculated using the usual capacitance formula given below, where all the symbols have the usual meaning and $C^{\prime}$ is the capacitance of the two electrode measurement.

$$
C^{\prime}=\frac{I t}{V m}
$$

Fig. 8a in $R S C A d v ., 2012,2,12322-12328$ clearly shows that the current density is $0.25 \mathrm{~A} \mathrm{~g}^{-1}$ and the discharge time is about less than 55 seconds. Using the abovementioned data in the capacitance equation, we obtained

$$
\begin{aligned}
C^{\prime} & =\frac{0.25 \times 55}{1} \\
& =13.75 \mathrm{~F} \mathrm{~g} \mathrm{~g}^{-1}
\end{aligned}
$$

The abovementioned two electrode capacitance is related to the three electrode capacitance: $:^{2,3}$

$$
C=4 C^{\prime}
$$

where only a capacitance of $55 \mathrm{~F} \mathrm{~g}^{-1}$ is obtained. However, Karthikeyan et al. ${ }^{\mathbf{1}}$ have reported that the capacitance is $88 \mathrm{~F} \mathrm{~g}^{-1}$ at $0.25 \mathrm{~A} \mathrm{~g}^{-1}$. There is a significant difference in the reported value and that given from the data in Fig. 8a. Furthermore, this discrepancy exists for all the current densities.

\section{Energy density and power density calculation as per the authors reported capacitance and actual capacitance}

The authors incorrectly reported the energy and power density calculation. For example, (energy density) the discharge time for the current density of $0.25 \mathrm{~A} \mathrm{~g}^{-1}$ is about 55 seconds, as given in Fig. 7a of the original article. The authors reported that the capacitance is about $88 \mathrm{~F} \mathrm{~g}^{-1}$, which has been used for further energy and power density calculations even though it is an incorrect value. Then, the energy density is calculated from the well-known energy density equation as follows:

$$
E=\frac{1}{2} C^{\prime} V^{2}
$$

where $C^{\prime}$ is the two electrode or device capacitance, which is related to ${ }^{2,3}$

$$
C=4 C^{\prime} \text { or } C^{\prime}=1 / 4 C
$$

By substituting $C^{\prime}$ in the abovementioned energy density equation, it becomes

$$
\begin{gathered}
E=\frac{1}{2 \times 4} C V^{2} \\
E=\frac{1}{8} C V^{2}
\end{gathered}
$$

where $E$ is the energy density, $C$ is the capacitance (which is equal to the three-electrode measurement), $V$ is the working voltage, which in this case is one according to the author. Energy density is calculated by substituting the corresponding values from the original article as follows:

$$
E=\frac{1}{8} C V^{2} ; \quad E=\frac{1}{8 \times 3.6} \times 88 \times 1^{2}
$$

$$
E=3.05 \mathrm{~W} \mathrm{~h} \mathrm{~kg}{ }^{-1}
$$

(In contrast, $11 \mathrm{~W} \mathrm{~h} \mathrm{~kg}^{-1}$ is reported in their study, which is nearly 4 times the actual energy density.)

The value of 3.6 is used as a conversion factor for time and mass (converted from seconds and grams to hours and kilograms, respectively, since the capacitance is given in Farads per gram). Therefore, the same correction needs to be applied for the energy density and the power density calculations for all the current densities. The reported values $11 \mathrm{~W} \mathrm{~h} \mathrm{~kg}^{-1}$ and $200 \mathrm{~W} \mathrm{~kg}^{-1}$ require about 198 seconds of discharge time, which is only 55 seconds in the original article, as given in Fig. 7a.

\section{Actual energy and density calculation}

The capacitance was calculated and found to be only $55 \mathrm{~F} \mathrm{~g}^{-1}$. Hence, the actual energy density was calculated as follows:

$$
\begin{gathered}
E=\frac{1}{8 \times 3.6} \times 55 \times 1^{2} \\
E=1.91 \mathrm{~W} \mathrm{~h} \mathrm{~kg}{ }^{-1}
\end{gathered}
$$

Only about $1.91 \mathrm{~W} \mathrm{~h} \mathrm{~kg}^{-1}$ is actually obtained, but this has been reported as $11 \mathrm{~W} \mathrm{~h} \mathrm{~kg}^{-1}$, which is nearly five times larger than the real energy density.

Power density $=$ energy density per hour.

Power density $=1.91 \mathrm{~W} \mathrm{~h} \mathrm{~kg}^{-1} / 0.0152$ hour (or 55 seconds) $=125 \mathrm{~W} \mathrm{~kg}^{-1}$, whereas $200 \mathrm{~W} \mathrm{~kg}^{-1}$ is reported in the original article. 


\section{Conclusions}

It is proven that the study reported by Karthikeyan et al. ${ }^{\mathbf{1}}$ in RSC Adv. (RSC Adv., 2012, 2, 12322-12328) contains incorrect data. This type of incorrect claim may complicate the authentic control of electrode material development and tactics for energy storage applications, thereby providing inconclusive data that will never work at all to the next generation of researchers. This comment paper will be greatly useful to future young researchers worldwide in the field of supercapacitors.

\section{Conflicts of interest}

There are no conflicts to declare.

\section{Acknowledgements}

I would like to thank Mrs Manjusha V. shelke (Scientist) and Mr Krishanamoorthy (Scientist) CSIR NCL, Pune, India, for providing great guidance.

\section{Notes and references}

1 K. Karthikeyan, D. Kalpana, S. Amaresh and Y. S. Lee, RSC Adv., 2012, 2, 12322-12328.

2 M. D. Stoller and R. S. Ruoff, Energy Environ. Sci., 2010, 3, 1294-1301.

3 Y. Zhu, S. Murali, M. D. Stoller, K. J. Ganesh, W. Cai, P. J. Ferreira, A. Pirkle, R. M. Wallace, K. A. Cychosz, M. Thommes, D. Su, E. A. Stach and R. S. Ruoff, Science, 2011, 332, 1537-1541. 